\title{
Direct interaction of iron-regulated surface determinant IsdB of Staphylococcus aureus with the GPIlb/llla receptor on platelets
}

\begin{abstract}
Correspondence
Timothy J. Foster

tfoster@tcd.ie
\end{abstract}

Received 24 November 2009

Accepted 9 December 2009

\author{
Helen Miajlovic, ${ }^{1}$ Marta Zapotoczna, ${ }^{1}$ Joan A. Geoghegan, ${ }^{1}$ \\ Steven W. Kerrigan, ${ }^{2}$ Pietro Speziale ${ }^{3}$ and Timothy J. Foster ${ }^{1}$ \\ ${ }^{1}$ Department of Microbiology, Moyne Institute of Preventive Medicine, Trinity College Dublin, \\ Dublin 2, Ireland \\ ${ }^{2}$ Department of Clinical Pharmacology, Royal College of Surgeons in Ireland, Dublin 2, Ireland \\ ${ }^{3}$ Department of Biochemistry, Viale Taramelli 3/b, 27100 Pavia, Italy
}

The interaction of bacteria with platelets is implicated in the pathogenesis of endovascular infections, including infective endocarditis, of which Staphylococcus aureus is the leading cause. Several $S$. aureus surface proteins mediate aggregation of platelets by fibrinogen- or fibronectindependent processes, which also requires specific antibodies. In this study $S$. aureus was grown in iron-limited medium to mimic in vivo conditions in which iron is unavailable to pathogens. Under such conditions, a $S$. aureus mutant lacking the known platelet-activating surface proteins adhered directly to platelets in the absence of plasma proteins and triggered aggregation. Platelet adhesion and aggregation was prevented by inhibiting expression of iron-regulated surface determinant (Isd) proteins. Mutants defective in IsdB, but not IsdA or IsdH, were unable to adhere to or aggregate platelets. Antibodies to the platelet integrin GPIlb/llla inhibited platelet adhesion by IsdB-expressing strains, as did antagonists of GPIllb/lla. Surface plasmon resonance demonstrated that recombinant IsdB interacts directly with GPIllb/lla.

\section{INTRODUCTION}

Staphylococcus aureus is an opportunistic pathogen that colonizes the desquamated epithelium of the anterior nares. At sites of infection such as wounds, ulcers or abscesses, S. aureus can gain access to the bloodstream, resulting in bacteraemia. Increased use of intravascular devices and invasive procedures in hospitals has led to an increased incidence of bacteraemic infections (Moreillon \& Que, 2004). Several endovascular infections, including infective endocarditis, result from the interaction of bacteria with platelets. S. aureus is the leading cause of infective endocarditis, which is characterized by the buildup, on heart-valve surfaces, of vegetative bodies consisting of bacteria, fibrin and aggregated platelets (Moreillon \& Que, 2004; Mylonakis \& Calderwood, 2001).

The ability of $S$. aureus and other bacteria to adhere to and aggregate platelets is thought to contribute to the development of endovascular infections. Aggregation of platelets by bacteria is the result of a multi-step process. Bacteria interact with receptors on the platelet surface either directly or indirectly through bridging molecules such as fibrinogen. Initial adhesion of bacteria to platelets

Abbreviations: GFP, gel-filtered platelets; PRP, platelet-rich plasma; WP, washed platelets. can result in subsequent platelet activation, which is characterized by signalling events and calcium oscillations within the platelet. Upon activation, the major platelet integrin GPIIb/IIIa undergoes conformational changes that allow it to bind avidly to fibrinogen and fibronectin in solution (Calvete, 1999). Aggregation of platelets occurs when adjacent platelets interact with the $\gamma$-chain of the bivalent fibrinogen molecule, cross-linking platelets into aggregates.

The interaction between $S$. aureus and platelets is complex and involves multiple factors (O'Brien et al., 2002). Several surface-expressed proteins can stimulate platelet aggregation. These include the fibrinogen-binding proteins clumping factors $\mathrm{A}$ and $\mathrm{B}$ (ClfA and ClfB), and the bifunctional fibronectin-fibrinogen binding proteins FnBPA and FnBPB (Fitzgerald et al., 2006b; Loughman et al., 2005; Miajlovic et al., 2007). Recent studies have shown that, under high shear rates such as those seen in small arteries and arterioles, protein A and ClfA are crucial for platelet aggregation (Kerrigan et al., 2008; Pawar et al., 2004).

Binding of fibrinogen or fibronectin by surface proteins effectively coats $S$. aureus with these two ligands, allowing it to engage the low-affinity form of the GPIIb/IIIa on resting platelets. Activation of platelets requires specific antibodies 
to the bacterial surface proteins to engage platelet receptor Fc $\gamma$ RIIa and trigger intracellular signalling events (Loughman et al., 2005; Miajlovic et al., 2007). A slower complement-dependent mechanism of activation was detected under circumstances where the major proaggregatory surface proteins were missing or defective (Ford et al., 1996; Loughman et al., 2005).

All studies on the interaction of $S$. aureus with platelets have been performed with bacterial cells grown in rich laboratory media replete with iron. In vivo, S. aureus has restricted access to iron and expresses iron-regulated surface determinant (Isd) proteins to capture haem from haemoglobin and transport it into the cell (Skaar et al., 2004; Skaar \& Schneewind, 2004). Two of the Isd proteins, IsdA and IsdH, are known to have other biological functions. IsdA interacts with an array of host proteins, and expression of IsdA by $S$. aureus also confers resistance to the innate defences of the human skin (Clarke et al., 2004, 2007, 2009). IsdH has been shown to play a role in evasion of phagocytosis as a result of accelerated degradation of the serum opsonin C3b (Visai et al., 2009). It is reasonable to predict that these major surface components of bacteria grown in vivo might also interact with platelets. This study investigated platelet adhesion and aggregation mediated by $S$. aureus strain Newman grown in an irondeficient medium. Using $S$. aureus mutants defective in various surface proteins, it was shown that IsdB binds to platelets by a direct interaction with the platelet integrin GPIIb/IIIa.

\section{METHODS}

Bacterial strains and growth conditions. The bacterial strains and plasmids used in this study are listed in Table 1. S. aureus strains were grown in at $37^{\circ} \mathrm{C}$ with shaking (200 r.p.m.) in RPMI 1640 (Sigma) to create iron-poor conditions. Lactococcus lactis was grown in GM17 medium with $3.2 \mathrm{ng}$ nisin $\mathrm{ml}^{-1}$. The following antibiotics (Sigma) were added to the media as required: chloramphenicol $(\mathrm{Cm})$ at $10 \mu \mathrm{g} \mathrm{ml}^{-1}$, erythromycin $(\mathrm{Em})$ at $10 \mu \mathrm{g} \mathrm{ml}^{-1}$ and tetracycline $(\mathrm{Tc})$ at $2 \mu \mathrm{g} \mathrm{ml} \mathrm{g}^{-1}$.

Construction of S. aureus strains. A frameshift mutation was constructed in the is $d B$ gene by replacing bases 10-14 with a BamHI restriction site. An upstream isdB sequence of $745 \mathrm{bp}$ was PCR amplified with primers $5^{\prime}$-GTCCTGCAGATTCTTACATTAGCTGACGCA- $3^{\prime}$ and $5^{\prime}$-GGCGGATCCTTTGTTCATGTTGTAGAAACA- $3^{\prime}$ and a downstream sequence of 904 bp was amplified with primers 5' -GAAGGATCCAAAAGAATTTAAATCATTTTA- ${ }^{\prime}$ ' and 5' CGCTCTAGAATCTTGAATTTTATTTAATTC- ${ }^{\prime}$. When the two fragments were ligated at the $B a m \mathrm{HI}$ site, $\mathrm{a}+1$ frameshift was created. The ligated fragments were cloned between the PstI and $\mathrm{XbaI}$ sites of plasmid pBluescript II-SK. This construct was then ligated with pTSermC using the XbaI sites in both plasmids to form pHM1. The temperature-sensitive shuttle plasmid bearing the is $d B$ mutation was transduced with phage 85 into Newman clfA and Newman clfA isdA. Growth of these strains at a restrictive temperature of $44{ }^{\circ} \mathrm{C}$ resulted in integration of the pHM1 plasmid into the chromosomal $i s d B$ gene. Plasmid excision was encouraged by growth of single integrants without selection at $28{ }^{\circ} \mathrm{C}$ followed by three cycles of growth in drug-free broth alternately at $44{ }^{\circ} \mathrm{C}$ and at $28{ }^{\circ} \mathrm{C}$ to enrich for plasmid-free excisants. Single colonies were isolated on drug-free agar and screened for sensitivity to erythromycin. Mutants were validated by PCR amplifying $1.6 \mathrm{~kb}$ is $d B$ genomic DNA, which was subsequently digested with BamHI. Strains containing the desired mutation had a novel BamHI restriction site present in isdB. Western

Table 1. Bacterial strains and plasmids

\begin{tabular}{|c|c|c|}
\hline Strain or plasmid & Relevant characteristics & Reference or source \\
\hline \multicolumn{3}{|l|}{ S. aureus } \\
\hline DU5999 & Newman clfA5, frameshift mutation in clfA & Fitzgerald et al. (2006b) \\
\hline Newman isdA & Newman deletion of isdA & Clarke et al. (2007) \\
\hline Newman clfA isdA & Newman clfA5, deletion of isdA & This study \\
\hline Newman clfA isdB & Newman clfA5, frameshift mutation in is $d B$ & This study \\
\hline Newman clfA clfB isdA & Newman clfA5, frameshift mutation in isdA, $c l f B:: \mathrm{Tc}^{\mathrm{R}}$ & This study \\
\hline Newman clfA clfB isdB & Newman clfA5, clfB: : lacZ $\mathrm{Em}^{\mathrm{R}}$, frameshift mutation in isdB & This study \\
\hline Newman clfA clfB isdA isdB & Newman clfA5, clfB:: lac $Z \mathrm{Em}^{\mathrm{R}}$, frameshift mutation in isd $A$ and is $d B$ & This study \\
\hline Newman clfA clfB isdH & Newman clfA5, clfB:: $\mathrm{Tc}^{\mathrm{R}}$, isdH:: $\mathrm{Em}^{\mathrm{R}}$ & This study \\
\hline \multicolumn{3}{|l|}{ L. lactis } \\
\hline NZ9800 & Derivative of MG1363, Tn5276, $\Delta$ nisA & Kuipers et al. (1993) \\
\hline pBlue $\Delta i s d B$ & pBluescript II SK containing is $d B$ DNA with frameshift mutation, $A m p^{\mathrm{R}}$ & This study \\
\hline pTSerm $C$ & S. aureus plasmid containing temperature-sensitive replicon, $\mathrm{Em}^{\mathrm{R}}$ & Fitzgerald et al. (2006b) \\
\hline pJH1 & Temperature-sensitive plasmid containing frameshift clfA5, $\mathrm{Em}^{\mathrm{R}}$ & Fitzgerald et al. (2006b) \\
\hline pHM1 & Shuttle plasmid containing pBlue $\Delta i s d B$ and pTSerm $C, A_{m p}{ }^{\mathrm{R}} / \mathrm{Em}^{\mathrm{R}}$ & This study \\
\hline pNZ8037clfB Q235A & pNZ8037clfB with point mutation at Q235A, $\mathrm{Cm}^{\mathrm{R}}$ & Miajlovic et al. (2007) \\
\hline
\end{tabular}


immunoblotting was also carried out to validate strains. Similarly, a frameshift mutation was introduced into the clfA gene in strain Newman isdA using pJH1, resulting in strain Newman clfA isdA.

To construct Newman clfA clfB isdA a clfA:: $\mathrm{Em}^{\mathrm{R}}$ mutation and a clfB:: $\mathrm{Tc}^{\mathrm{R}}$ mutation were transduced into strain Newman isdA. Strain Newman clfA clfB is $B B$ was constructed by transducing $\operatorname{clfB}:: \mathrm{Em}^{\mathrm{R}}$ into strain Newman clfA isdB. The clfB:: $\mathrm{Em}^{\mathrm{R}}$ mutation was transduced into Newman clfA isdA isdB to create Newman clfA clfB is $d A$ is $d B$. Finally, strain Newman $c l f A$ clfB is $d H$ was constructed by transducing isdH:: $\mathrm{Em}^{\mathrm{R}}$ and $c l f B:: \mathrm{Tc}^{\mathrm{R}}$ into strain Newman clfA.

Western immunoblotting. Cultures of $S$. aureus grown in RPMI for $18 \mathrm{~h}$ at $37{ }^{\circ} \mathrm{C}$ were washed twice in PBS and adjusted to an $\mathrm{OD}_{600}$ of 10 in $250 \mu \mathrm{l}$ of $20 \mathrm{mM}$ Tris ( $\mathrm{pH} 8$ ), $10 \mathrm{mM} \mathrm{MgCl}_{2}$ containing $30 \%$ $(\mathrm{w} / \mathrm{v})$ raffinose. Complete EDTA-free protease inhibitor cocktail (Roche) and lysostaphin $\left(200 \mu \mathrm{g} \mathrm{ml}^{-1}\right.$; AMBI) were added to the cells and incubated at $37{ }^{\circ} \mathrm{C}$ for $10 \mathrm{~min}$. Protoplasts were sedimented by centrifugation at 5000 r.p.m. for $10 \mathrm{~min}$ (Hartford et al., 2001). The cell-wall fraction was separated on $7.5 \%(\mathrm{w} / \mathrm{v})$ polyacrylamide gels, transferred onto PVDF membranes (Roche) and blocked in $10 \%$ (w/v) skimmed milk (Marvel). Membranes were probed with polyclonal anti-IsdB and anti-IsdA at a dilution of $1: 5000$ and with polyclonal anti-IsdH antibodies at a dilution of $1: 10000$.

Preparation of platelet-rich plasma. Platelet-rich plasma (PRP) was prepared as described previously (Loughman et al., 2005). Briefly, human blood was drawn into a syringe containing $3.2 \%(\mathrm{w} / \mathrm{v})$ sodium citrate. Whole blood was centrifuged at $150 \mathrm{~g}$ for $10 \mathrm{~min}$. The top layer, consisting of PRP, was removed. Platelet aggregation was measured using light transmission aggregometry. Aggregation of platelets occurred after a variable period of time referred to as the lag time. This time reflects the time taken for aggregation to occur after bacteria and platelets come into contact. Overall percentage aggregation was also measured.

Preparation of washed platelets. Blood was drawn into a syringe containing acid-citrate-glucose (ACD, $25 \mathrm{mM}$ citric acid, $75 \mathrm{mM}$ sodium citrate, $135 \mathrm{mM}$ D-glucose). Following preparation of PRP the $\mathrm{pH}$ of the platelets was adjusted to 6.5 using ACD. Prostaglandin E1 ( $1 \mu \mathrm{M}$; Sigma) was added to prevent activation of platelets during centrifugation. PRP was centrifuged at $720 \mathrm{~g}$ for $10 \mathrm{~min}$. The supernatant was carefully removed and discarded. The platelet pellet was resuspended in $1 \mathrm{ml}$ fresh JNL buffer ( $6 \mathrm{mM}$ D-glucose, $130 \mathrm{mM}$ $\mathrm{NaCl}, 9 \mathrm{mM} \mathrm{NaHCO} 3,10 \mathrm{mM}$ sodium citrate, $10 \mathrm{mM}$ Tris, $3 \mathrm{mM}$ $\mathrm{KCl}, 0.8 \mathrm{mM} \mathrm{KH}_{2} \mathrm{PO}_{4}$ and $0.9 \mathrm{mM} \mathrm{MgCl} ; \mathrm{pH} \mathrm{7.4)}$ and diluted to obtain a platelet count of $3 \times 10^{8}$ platelets $\mathrm{ml}^{-1}$

Preparation of gel-filtered platelets. Washed platelets (WP) were passed through a $10 \mathrm{ml}$ Sepharose 2B column (Sigma). Gel-filtered platelets (GFP) were collected and diluted to obtain a platelet count of $3 \times 10^{8}$ platelets $\mathrm{ml}^{-1}$. WP and GFP were supplemented with $2 \mathrm{mM}$ $\mathrm{CaCl}_{2}$.

Removal of IgG from commercial supplies of fibrinogen and from human serum. IgG present in commercial fibrinogen and in serum was removed by passage through a column of protein A coupled to Sepharose (Amersham Biosciences). Depletion of IgG was confirmed by ELISA using protein A-peroxidase (Sigma). Human serum was diluted $1: 20$ and analysed by SDS-PAGE to confirm loss of IgG.

Inactivation of complement proteins in human serum. Complement components were inactivated in human serum by heating to $56{ }^{\circ} \mathrm{C}$ for $30 \mathrm{~min}$.

Platelet adhesion assay. Cultures of bacterial strains were pelleted by centrifugation, washed in PBS and resuspended to an $\mathrm{OD}_{600}$ of 1 .
Wells of microtitre plates were coated with $100 \mu$ bacteria and incubated for $16 \mathrm{~h}$ at $4{ }^{\circ} \mathrm{C}$, washed with PBS and blocked with $1 \%$ BSA (w/v; $100 \mu \mathrm{l})$ for $90 \mathrm{~min}$ at $37^{\circ} \mathrm{C}$. Wells were washed with JNL buffer and $50 \mu \mathrm{l} \mathrm{WP}$ was added. Plates were incubated at $37{ }^{\circ} \mathrm{C}$ for $40 \mathrm{~min}$ and washed subsequently with JNL buffer. Adherent platelets were measured with a lysis buffer containing a substrate for acid phosphatase $[100 \mathrm{mM}$ sodium acetate, $0.1 \%(\mathrm{v} / \mathrm{v})$ Triton X-100, $10 \mathrm{mM}$ p-nitrophenol phosphate (Sigma)]. Absorbance at $405 \mathrm{~nm}$ was read in an ELISA plate reader. Equal coating of plates with $S$. aureus strains was confirmed by fixing adherent cells with $25 \%(\mathrm{v} / \mathrm{v})$ formaldehyde and staining with of $0.5 \%(\mathrm{w} / \mathrm{v})$ crystal violet.

Platelet aggregation. Bacterial cells were washed with PBS, resuspended to an $\mathrm{OD}_{600}$ of 1.6 and $25 \mu \mathrm{l}$ washed cells was added to $225 \mu \mathrm{l}$ PRP in siliconized flat-bottom glass cuvettes (BioData). PRP and bacteria were incubated with stirring (900 r.p.m.) in an aggregometer (Bio-Data) at $37{ }^{\circ} \mathrm{C}$. Light transmission was monitored for $25 \mathrm{~min}$. Inhibitors tested were anti-GPIIb/IIIa (Abciximab, Eli Lily) antibodies at a $1 / 100$ dilution, anti-Fc $\gamma$ RIIa (Medarex) antibodies at a $1 / 50$ dilution and anti-GPIb monoclonal antibody (AN51, Dako) at a 1/50 dilution. RGD peptide and tirofiban (Merck) were used at $10 \mathrm{mM}$ and $2 \mu \mathrm{M}$ respectively. GFP were supplemented with purified fibrinogen at a final concentration of $0.5 \mathrm{mg} \mathrm{ml}^{-1}$. Pooled human IgG (Baxter) was added to GFP to a final concentration of $2 \mu \mathrm{g} \mathrm{ml}^{-1}$. Twenty-five microlitres of human serum was added to a final volume of $225 \mu \mathrm{GFP}$.

GPIIb/IIla-binding assay. Microtitre plates were coated for $16 \mathrm{~h}$ with $100 \mu \mathrm{g} \mathrm{ml}^{-1}$ of GPIIb/IIIa (Calbiochem). Plates were washed with PBS and blocked with $1 \%(\mathrm{w} / \mathrm{v}) \mathrm{BSA}$ for $2 \mathrm{~h}$ at $37^{\circ} \mathrm{C}$. Bacteria were stained with a fluorescent stain (Cyber), adjusted to an $\mathrm{OD}_{600}$ of 0.5 and added to GPIIb/IIIa-coated plates. Following a $40 \mathrm{~min}$ incubation at $37^{\circ} \mathrm{C}$, plates were washed with PBS and fluorescence units read at $485-535 \mathrm{~nm}$. Values were adjusted by subtracting binding to BSA.

Purification of recombinant IsdB. DNA encoding residues $48-480$ of IsdB was amplified from the genomic DNA of strain Newman using primers Fis $d B$ 5'-GGCCATGGATCCACAAATACAGAAGCACAACCAAA-3' and Ris ${ }^{\prime} B$ 5'-GGCCATCCTGCAGAGTAGCTTCCTTCTTAGCTGA- $3^{\prime}$. The is $d B$ coding sequence was cloned between the BamHI and PstI sites in pQE30. pQE30 isdB was transformed into Escherichia coli strain TOPP3 and IsdB expression was induced with $1 \mathrm{mM}$ IPTG. Recombinant rIsdB 48-480 was purified by $\mathrm{Ni}^{2+}$ affinity chromatography as described previously (O’Connell et al., 1998).

Surface plasmon resonance. Surface plasmon resonance (SPR) was performed using the BIAcore X100 system (GE Healthcare). GPIIb/IIIa (Enzyme Research Laboratories) was covalently immobilized on CM5 sensor chips using amine coupling. This was performed using 1-ethyl-3-(3-dimethylaminopropyl) carbodiimide hydrochloride (EDC), followed by $\mathrm{N}$-hydroxysuccinimide (NHS) and ethanolamine hydrochloride, as described by the manufacturer. GPIIb/IIIa $\left(100 \mu \mathrm{g} \mathrm{ml}^{-1}\right)$ was dissolved in $10 \mathrm{mM}$ sodium acetate (with $1 \mathrm{mM} \mathrm{MgCl}_{2}$ and $1 \mathrm{mM} \mathrm{CaCl}_{2}$ ) at $\mathrm{pH} 4.5$ and then immobilized on the flow cell at a flow rate of $30 \mu \mathrm{min}^{-1}$ in HEPES-buffered saline. On another flow cell, the dextran matrix was treated as described above but without GPIIb/IIIa present to provide an uncoated reference flow cell. Increasing concentrations of rIsdB were flowed over immobilized GPIIb/IIIa and the reference flow cell at a rate of $5 \mu \mathrm{min}^{-1}$.

The sensorgram data presented were subtracted from the corresponding data from the reference flow cell. The response generated from injection of buffer over the chip was also subtracted from all sensorgrams. Data were analysed using the BIAevaluation software 
version 3.0. The equilibrium dissociation constant $\left(K_{\mathrm{D}}\right)$ was obtained by globally fitting the data using the Langmuir $1: 1$ binding model.

Statistical analysis. The data presented by this study represent the means $\pm S D$ of three experiments unless otherwise stated. The unpaired $t$-test was used to determine the significance of differences in aggregation between strains, with significance defined as $P<0.05$.

\section{RESULTS}

\section{Platelet adhesion and aggregation mediated by iron-starved $\mathbf{S}$. aureus}

S. aureus Newman mediates adhesion to and aggregation of platelets using surface proteins ClfA and ClfB. In strain Newman the FnBPA and FnBPB surface proteins are not expressed on the cell surface due to nonsense mutations at the $3^{\prime}$ ends of the genes and therefore do not contribute to platelet aggregation (Grundmeier et al., 2004). In order to investigate the possibility that Isd proteins adhere to and aggregate platelets in the absence of known proaggregatory surface proteins, strain Newman with mutations in clfA and $c l f B$ was studied.

Microtitre dishes were coated with Newman $\operatorname{clf} A$ clfB that had been grown in the iron-restricted medium RPMI. Washed platelets (WP) adhered strongly to the bacteria at a level twofold higher than to control wells coated with immobilized fibrinogen $(P<0.0001$, Fig. 1a). Adherence of platelets to bacteria occurred without the addition of exogenous fibrinogen. Growth of bacteria in RPMI with $50 \mu \mathrm{M} \mathrm{FeCl}{ }_{3}$ eliminated adhesion of WP to immobilized bacteria $(P<0.0001)$. These results suggest that direct adherence of strain Newman to platelets is dependent on proteins induced by iron starvation.
Platelet aggregation by RPMI-grown Newman $\operatorname{clf} A$ clfB was measured by light transmission with an aggregometer. Aggregation occurred with a mean lag time of $5.6 \pm 0.67 \mathrm{~min}$ at an overall percentage aggregation of $60 \pm 4 \%$. Growth of Newman clfA clfB in RPMI supplemented with $50 \mu \mathrm{M} \mathrm{FeCl}$ eliminated platelet aggregation (Fig. 1b). These results indicate that proteins induced by iron starvation can also trigger platelet aggregation possibly by the direct interaction shown in Fig. 1(a).

\section{Newman isd mutants}

In order to determine whether the surface-exposed Isd proteins IsdA, IsdB or IsdH interact with platelets, mutants of Newman $\operatorname{clf} A$ clfB that lacked each of these proteins were constructed. The mutants were studied by Western immunoblotting to ensure that each lacked the relevant Isd protein and still produced the other Isd proteins.

The $38 \mathrm{kDa}$ IsdA protein could not be detected in solubilized cell-wall extracts of Newman clfA clfB isdA whereas IsdB and IsdH proteins could be detected (Fig. 2). Strain Newman clfA $\operatorname{clfB}$ isdB expressed $38 \mathrm{kDa}$ IsdA and $150 \mathrm{kDa}$ IsdH proteins, whereas IsdB was absent. Newman clfA clfB is $d A$ is $d B$ lacked IsdA and IsdB, whereas IsdH was detected. IsdH was not expressed by Newman clfA clfB isdH whereas IsdA and IsdB were present (Fig. 2).

\section{Platelet adhesion and aggregation mediated by Newman isd mutants}

Bacterial strains were grown in RPMI for $16 \mathrm{~h}$ at $37^{\circ} \mathrm{C}$. Cells were washed and added to microtitre plates and tested for their ability to support binding of WP. Platelets adhered avidly to strain Newman clfA clfB. Mutations in (a)

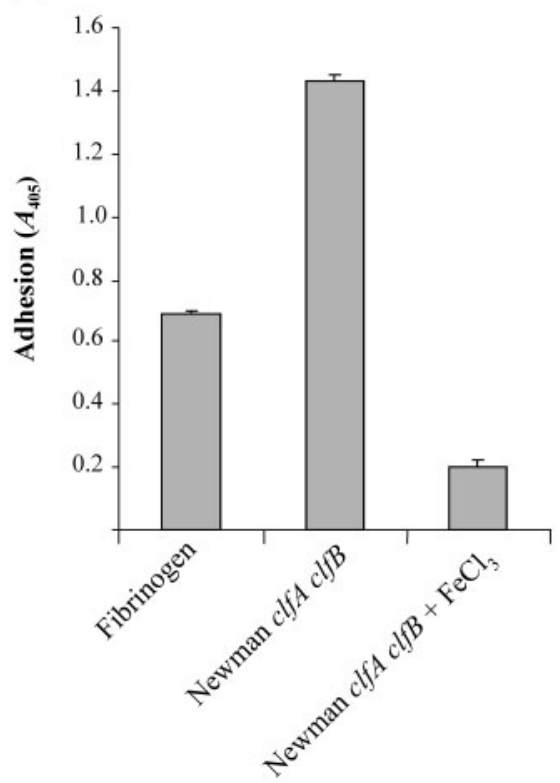

(b)

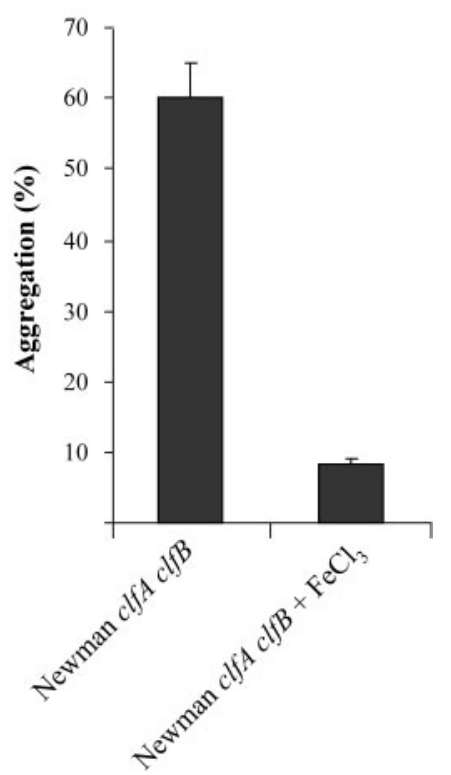

Fig. 1. Platelet adhesion and aggregation mediated by RPMl-grown S. aureus. Newman ClfA clfB was grown in RPMI with or without the addition of $50 \mu \mathrm{M} \mathrm{FeCl}$. (a) Washed platelets were added to microtitre wells coated with bacteria or $50 \mu \mathrm{g}$ fibrinogen $\mathrm{ml}^{-1}$. Adherent platelets were lysed and detected with a substrate for intracellular acid phosphatase. Results are means $\pm S D$. (b) Washed bacterial cells were added to PRP in an aggregometer. Results are means \pm SD of light transmission (percentage aggregation) observed after $25 \mathrm{~min}$. 


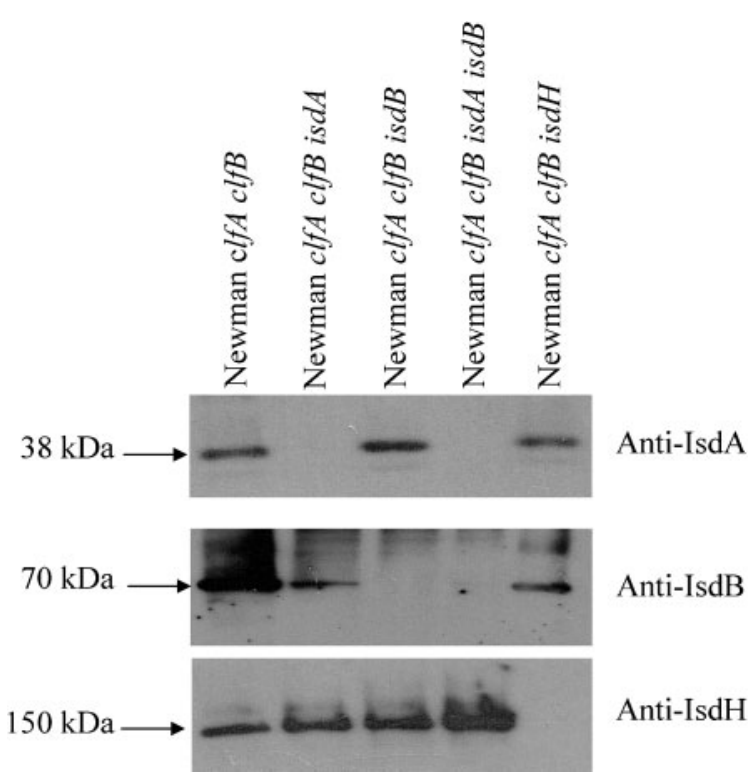

Fig. 2. Characterization of Newman isd mutants. The strains indicated were grown to stationary phase in RPMI. Cell-wall proteins were solubilized by lysostaphin digestion, separated on $7.5 \%$ SDS-PAGE gels and electroblotted onto PVDF membranes. Membranes were probed with polyclonal anti-IsdA, anti-IsdB and anti-lsdH and bound antibodies were detected with HRPconjugated protein A-peroxidase. either isdA or isdH had little or no effect on adhesion of platelets (Fig. 3a). In contrast, strain Newman clf $A$ clfB is $d B$ was unable to support adherence of WP $(P<0.0001)$. Eliminating IsdA did not significantly lower adhesion $(P=0.3609$; Fig. $3 \mathrm{a})$. These results suggest that IsdB is the protein responsible for adhesion to platelets under ironlimiting conditions.

Newman clfA clfB cells that had been grown under ironrestricted conditions caused platelet aggregation in PRP with a lag time of $5.6 \pm 0.67 \mathrm{~min}$. Mutants lacking either IsdA or IsdH were able to promote aggregation of platelets, with no significant differences in the percentage aggregation or lag time to aggregation $(P=0.46$ and $P=0.68$, respectively). In contrast, the $i s d B$ mutant failed to cause platelet aggregation $(P=0.0002$; Fig. $3 \mathrm{~b})$. The mutant lacking both IsdB and IsdA was also unable to support platelet aggregation. IsdB appears to be crucial for both adhesion to and aggregation of platelets by iron-starved $S$. aureus cells.

\section{Plasma proteins required for platelet aggregation mediated by IsdB}

Lag times to aggregation for Newman clfA clfB grown in RPMI varied with plasma donor, with a mean lag time of $5.6 \pm 0.67 \mathrm{~min}$. Longer lag times are often associated with complement-mediated platelet activation (Ford et al., 1996; Loughman et al., 2005). To further investigate the (a)

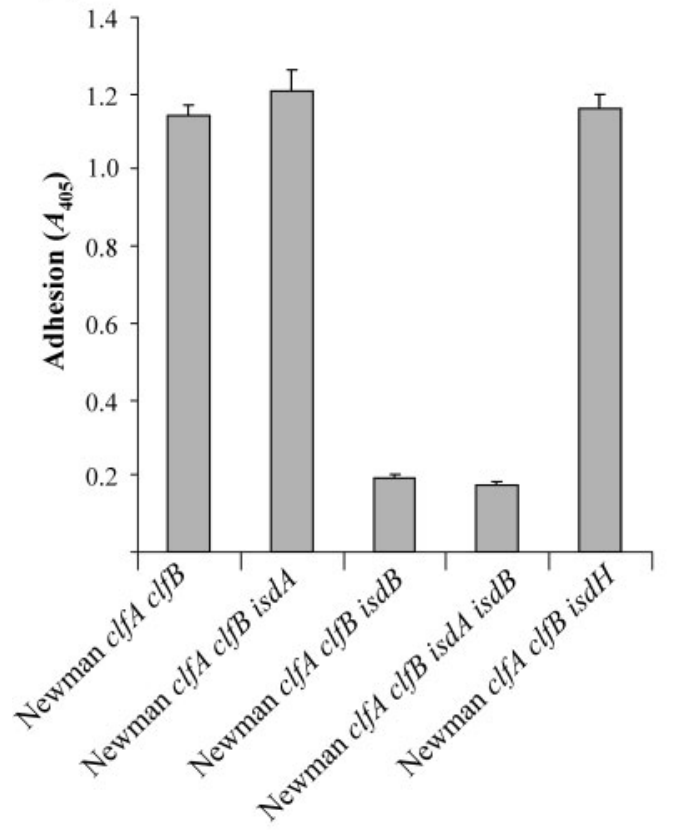

(b)

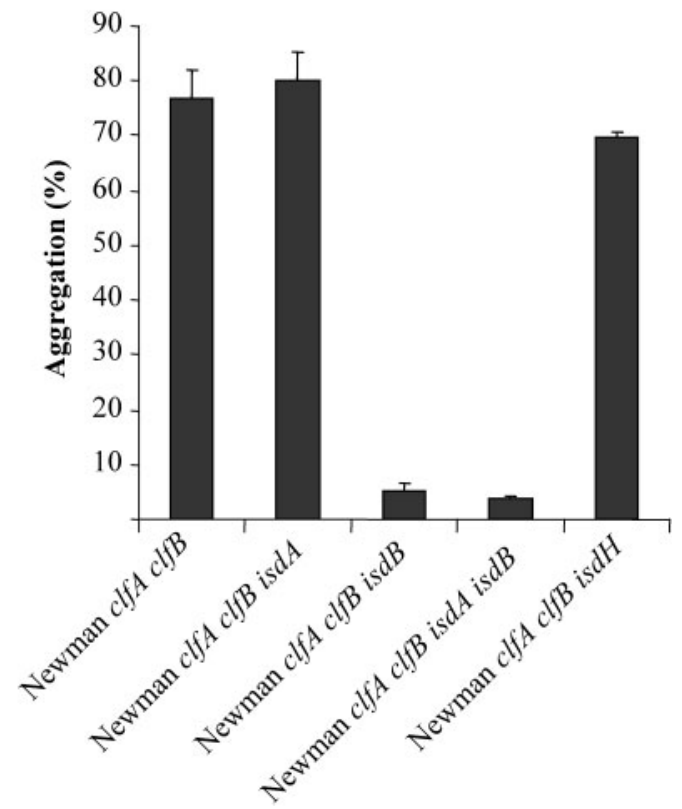

Fig. 3. Platelet adhesion and aggregation mediated by Newman isd mutants. (a) WP were added to microtitre wells coated with bacterial cells. Adherent platelets were lysed and detected with a substrate for intracellular acid phosphatase. Results are means \pm SD. (b) Washed bacterial cells were added to PRP in an aggregometer. Results are means $\pm S D$ of light transmission (percentage aggregation) observed after $25 \mathrm{~min}$. 
mechanism of platelet aggregation, complement was inactivated in human serum by heat treatment. Serum depleted of IgG was also utilized to determine the necessity for antibodies. L. lactis NZ9800(pNZ8037 clfB Q235A), expressing ClfB Q235A, was used as negative control in this assay. ClfB Q235A lacks the ability to bind to fibrinogen and therefore cannot activate platelets in a fibrinogendependent manner. Activation of platelets by L. lactis ClfB Q235A is complement dependent and requires IgG. This strain does not cause aggregation of gel-filtered platelets (GFP) in the presence of fibrinogen and complementinactivated serum or IgG-depleted serum (Miajlovic et al., 2007).

Both Newman clfA clfB and L. lactis ClfB Q235A were able to stimulate aggregation of GFP supplemented with fibrinogen and $10 \%$ human serum (Fig. 4a). Adding heated serum or IgG-depleted serum to GFP did not support platelet aggregation mediated by $L$. lactis ClfB Q235A. In contrast, Newman clfA clfB was able to cause aggregation in GFP supplemented with heated serum and IgG-depleted serum. No significant difference in the percentage aggregation was observed between GFP supplemented with serum, heated serum or IgG-depleted serum $(P=0.1155$ and $P=0.2758$, respectively). Likewise, no significant difference was observed in the lag time to aggregation. Thus platelet aggregation mediated by Newman clfA clfB grown in ironlimiting conditions is not complement dependent and IgG does not seem to be necessary.

Further experiments were carried out to identify the mechanism of platelet aggregation. Iron-starved bacterial cells were added to GFP supplemented with purified fibrinogen lacking contaminating $\operatorname{IgG}$ present in commercial supplies. Strain Newman expressing IsdB was able to stimulate aggregation of GFP supplemented with fibrinogen alone (Fig. 4b). The addition of exogenous IgG decreased the mean lag time to aggregation from $4.33 \pm 1.86 \mathrm{~min}$ to $2.33 \pm 0.88 \mathrm{~min}$. However, this difference was not statistically significant $(P=0.121)$ due to considerable variations in lag time between donors. Strain Newman clfA clfB is $B$ was unable to cause activation of GFP supplemented with fibrinogen alone or with fibrinogen and $\operatorname{IgG}$ together.

\section{Inhibition of platelet adhesion}

Washed platelets were incubated with antibodies that are known to block receptors GPIIb/IIIa, Fc $\gamma$ RIIa and GP1b prior to their addition to microtitre plates coated with bacteria. The anti-GPIIb/IIIa monoclonal antibody abciximab inhibited adherence of WP to RPMI-grown Newman clfA clfB $(P<0.0001$, Fig. 5a). Monoclonal antibodies IV3 and AN51, which block the Fc $\gamma$ RIIa and GP1b, respectively, did not significantly inhibit adhesion of WP to Newman clfA clfB (Fig. 5a). This indicates that adherence of platelets to iron-starved $S$. aureus occurs via GPIIb/IIIa and does not involve GP1b or Fc $\gamma$ RIIa.

In order to confirm that IsdB interacts with GPIIb/IIIa, inhibition experiments were carried out with GPIIb/IIIa antagonists. GPIIb/IIIa recognizes an RGD motif present in fibrinogen and fibronectin. Synthetic RGD peptide and tirofiban, a specific inhibitor of GPIIb/IIIa, were tested for
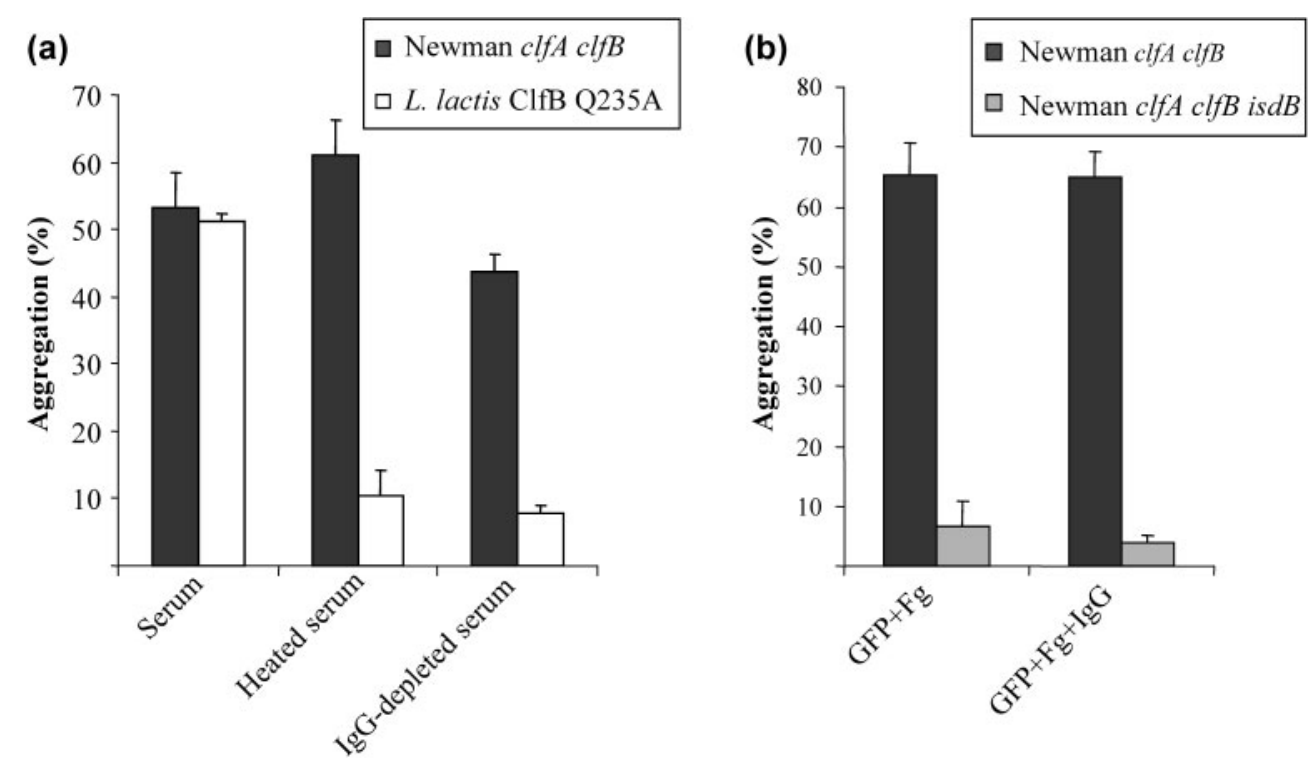

Fig. 4. Role of complement and lgG in platelet aggregation. (a) Strains $L$. lactis ClfB $Q 235 A$ and Newman clfA clfB were washed and added to GFP supplemented with fibrinogen $(\mathrm{Fg})$ and $10 \%$ human serum (heated to $56{ }^{\circ} \mathrm{C}$ or $\operatorname{lgG}$ depleted). (b) Washed bacterial cells were added to GFP supplemented with $1 \mathrm{mg} \mathrm{Fg} \mathrm{ml}^{-1}$, with or without the addition of pooled human lgG. Results are means \pm SD of light transmission (percentage aggregation) observed after 25 min. 
(a)

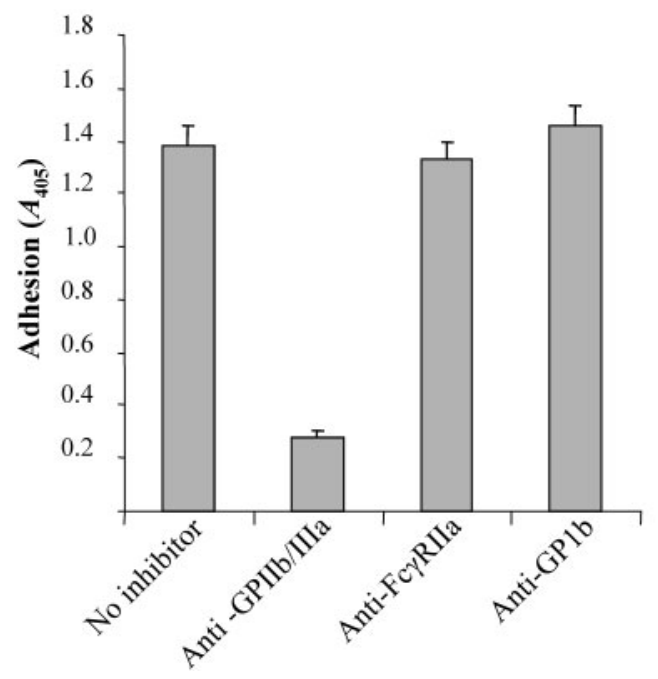

(b)

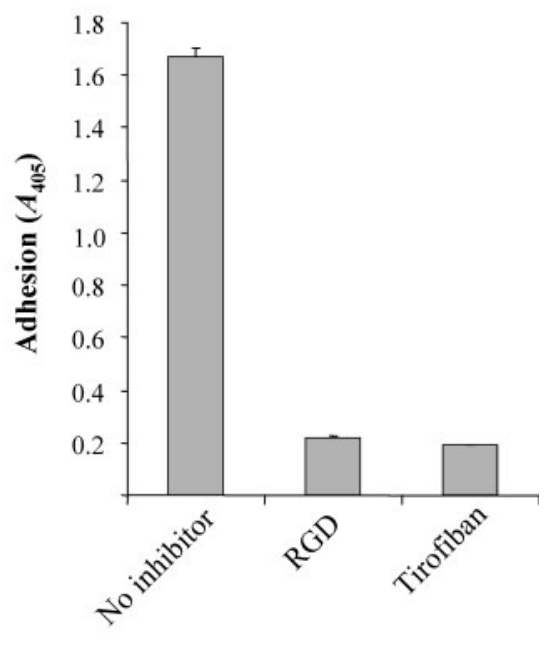

Fig. 5. Effect of platelet receptor inhibitors on adhesion. (a) WP were incubated for 15 min at $37{ }^{\circ} \mathrm{C}$ with inhibitory antibodies to platelet receptors and added to microtitre plates coated with RPMl-grown Newman clfA clfB. (b) WP were incubated for 15 min at $37{ }^{\circ} \mathrm{C}$ with RGD peptide or tirofiban and added to microtitre plates coated with RPMl-grown Newman clfA clfB. Adherent platelets were lysed and detected with a substrate for intracellular acid phosphatase. Results are means \pm SD.

their ability to inhibit adhesion of platelets to iron-starved Newman clfA clfB. Both RGD peptide and tirofiban inhibited adhesion of platelets $(P<0.0001$ in both cases, Fig. 5b).

\section{Direct interaction of IsdB and GPIIb/IIla}

Purified GPIIb/IIIa was coated onto microtitre plates. The ability of iron-starved Newman clfA clfB and Newman clfA $c l f B$ is $d B$ to adhere to the immobilized integrin was measured. Newman clfA clfB adhered to immobilized GPIIb/IIIa but the is $d B$ mutant failed to do so (Fig. 6a). Eliminating IsdB from Newman clfA clfB inhibited binding to GPIIb/IIIa $(P=0.0089)$, confirming the direct interaction between these proteins.

Surface plasmon resonance was also used to demonstrate a direct interaction between IsdB and GPIIb/IIIa (Fig. 6b). Increasing concentrations of recombinant IsdB were flowed over a chip that had been coated with GPIIb/IIIa. The approximate dissociation constant $\left(K_{\mathrm{D}}\right)$ of the interaction was determined to be $405 \pm 73.7 \mathrm{nM}$, indicating that IsdB directly interacts with GPIIb/IIIa with a high affinity.

\section{DISCUSSION}

The ability of $S$. aureus to adhere to and activate platelets is believed to be an important factor in the pathogenesis of cardiovascular infections, including infective endocarditis. Previous studies have established that $S$. aureus surface proteins ClfA, ClfB, FnBPA and FnBPB can promote activation of platelets (Fitzgerald et al., 2006a). These studies were carried out with bacteria grown in complex iron-containing media. This study investigated platelet adhesion and aggregation mediated by bacteria that were grown in an iron-deficient medium to mimic more closely the in vivo environment.

Initial adhesion of bacteria to platelets is required to trigger subsequent platelet activation. A common mechanism for platelet activation has been identified for bacterial proteins capable of binding to the blood glycoproteins fibrinogen and fibronectin. ClfA and ClfB of $S$. aureus mediate adhesion to platelets via a fibrinogen bridge to platelet receptor GPIIb/IIIa (Loughman et al., 2005; Miajlovic et al., 2007). Under iron-restricted growth conditions the adhesion of $S$. aureus lacking these proteins to platelets was direct and did not require fibrinogen (Fig. 1a). Elimination of IsdB from the cell surface by growth in the presence of iron or by mutation of the is $d B$ gene resulted in loss of platelet adhesion (Figs 1a and 3a). IsdH or IsdA were not required to promote platelet adhesion, as strains lacking these proteins were able to adhere at wild-type levels (Fig. 3a).

In order to identify the receptor for IsdB on the platelet surface, inhibitors of the major platelet receptors were utilized. Adhesion to platelets was only inhibited by function-blocking antibodies to receptor GPIIb/IIIa (Fig. 5a). GPIIb/IIIa is the most abundant receptor found on the platelet surface. It recognizes RGD motifs present in multiple ligands, including fibrinogen and fibronectin, to promote platelet adhesion at sites of thrombus formation. Tirofiban, a specific inhibitor of GPIIb/IIIa function, completely inhibited adhesion of platelets (Fig. 5b). 
(a)

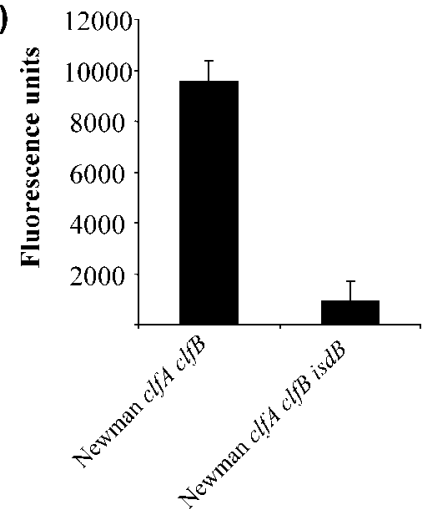

(b)

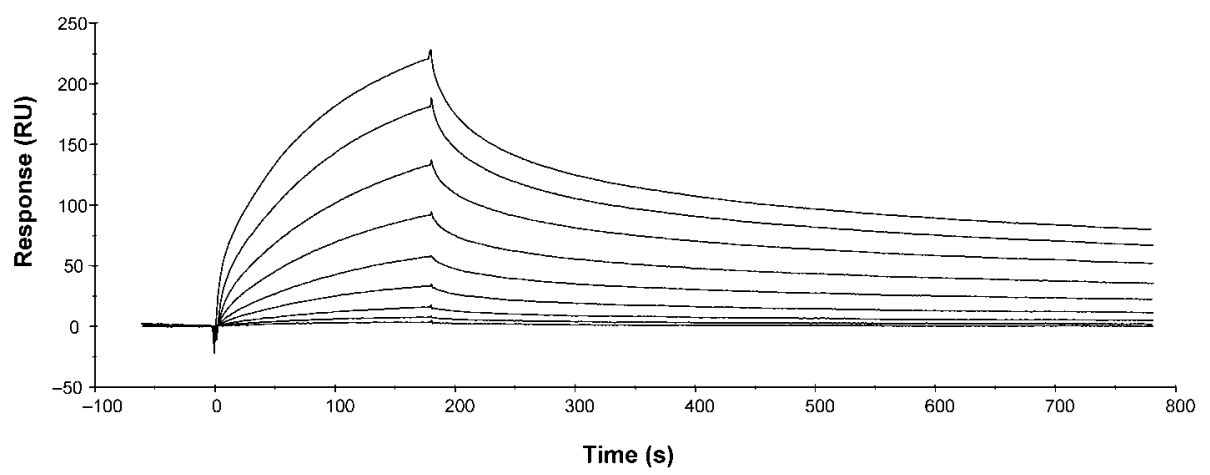

Fig. 6. Direct interaction of IsdB with GPIlb/llla. (a) Bacterial strains were fluorescently stained and incubated at $37{ }^{\circ} \mathrm{C}$ in microtitre plates coated with GPIlb/llla. Plates were washed and fluorescence units read at 485-535 nm (three readings in each of two experiments). Results are means \pm SD. (b) GPllb/llla was immobilized on the surface of a CM5 sensor chip. Sensorgrams of the binding to GPllb/llla were obtained by passing increasing concentrations of rlsdB over the surface. Injections began at $0 \mathrm{~s}$ and ended at $180 \mathrm{~s}$. Results shown are representative of two independent experiments.

Incubating platelets with soluble RGD peptide also inhibited adhesion of platelets to bacteria expressing IsdB, indicating that IsdB binds to the GPIIb/IIIa receptor on platelets.

To demonstrate that IsdB interacts directly with GPIIb/IIIa, it was shown that $S$. aureus strain Newman clfA clfB adhered to purified GPIIb/IIIa in an IsdB-dependent fashion (Fig. 6a). The direct nature of the interaction between IsdB and GPIIb/IIIa was confirmed by surface plasmon resonance (Fig. 6b). IsdB bound to GPIIb/IIIa with a high affinity (approximate $K_{\mathrm{D}} 405 \pm 73.7 \mathrm{nM}$ ). Previous studies carried out with $\mathrm{IsdH}$ have shown that the residues in the fuctional NEAT I domain were crucial for both haemoglobin binding and evasion of phagocytosis (Visai et al., 2009). The NEAT domain of IsdB does not have an integrin-binding RGD motif. Further studies will be carried out in this laboratory to characterize the GPIIb/ IIIa-binding epitope in IsdB by substituting residues in the NEAT domains.

Aggregation of platelets following adhesion was dependent on expression of IsdB and occurred after a lag time of $5.6 \pm 0.67 \mathrm{~min}$. Longer lag times to activation are sometimes associated with complement-dependent platelet activation and reflect the time taken for complement fixation to occur on the bacterial cell surface. However, in this case aggregation was not complement dependent and occurred when complement proteins were lacking or inactivated (Fig. 4).

Bacteria expressing either clumping factors or fibronectinbinding proteins require specific IgG to trigger platelet aggregation. The only plasma factor necessary for platelet aggregation mediated by $\mathrm{IsdB}$ was fibrinogen, to allow cross-linking of platelets into aggregates (Fig. 4b). IgG did not seem to be directly required for aggregation since the addition of fibrinogen alone to GFP was sufficient to allow aggregation. However, there was a trend towards a faster lag time in the presence of IgG. This needs to be investigated further with more donors. It is possible that engagement of the Fc receptors on platelets by IgG will promote faster aggregation by triggering a second signalling event. The primary event is outside-in signalling mediated by IsdB binding to the low-affinity form of GPIIb/IIIa. To our knowledge, this is the first report of direct interaction of a $S$. aureus surface protein with GPIIb/ IIIa. However, recent studies have shown that the platelet adhesion protein (PadA) of Streptococcus gordonii can directly bind to GPIIb/IIIa on platelets to promote adhesion but not aggregation (Petersen et al., 2009). Other direct mechanisms of platelet aggregation have also been identified. Streptococcus sanguis expressing SrpA can mediate aggregation of platelets through direct binding to GP1b without the requirement for IgG (Kerrigan et al., 2002).

IsdB-mediated platelet aggregation may be of relevance in vivo, particularly if other proaggregatory molecules are expressed at lower levels than when bacteria are grown in rich broth. Although ClfB was expressed at constant high levels from $S$. aureus grown in RPMI, expression of ClfA was dramatically reduced compared to that seen from cells grown in rich broth (data not shown). Induction of IsdB expression in vivo is likely to provide a mechanism of platelet aggregation that is independent of clumping factors and FnBPs. It will be interesting to determine if the Isdpromoted mechanism of platelet aggregation is of significance in bacteria that express clumping factors and FnBPs.

This study has identified a novel mechanism of platelet aggregation for $S$. aureus expressing Isd proteins, in which IsdB binds directly to the resting form of platelet integrin GPIIb/IIIa. Proteins such as IsdB whose expression is induced by the harsh growth environment in vivo may be 
important in mediating platelet aggregation and thrombus formation in the human host.

\section{ACKNOWLEDGEMENTS}

This work was supported by the Health Research Board of Ireland.

\section{REFERENCES}

Calvete, J. J. (1999). Platelet integrin GPIIb/IIIa: structure-function correlations. An update and lessons from other integrins. Proc Soc Exp Biol Med 222, 29-38.

Clarke, S. R., Wiltshire, M. D. \& Foster, S. J. (2004). IsdA of Staphylococcus aureus is a broad spectrum, iron-regulated adhesin. Mol Microbiol 51, 1509-1519.

Clarke, S. R., Mohamed, R., Bian, L., Routh, A. F., Kokai-Kun, J. F., Mond, J. J., Tarkowski, A. \& Foster, S. J. (2007). The Staphylococcus aureus surface protein IsdA mediates resistance to innate defenses of human skin. Cell Host Microbe 1, 199-212.

Clarke, S. R., Andre, G., Walsh, E. J., Dufrene, Y. F., Foster, T. J. \& Foster, S. J. (2009). Iron-regulated surface determinant protein A (IsdA) mediates adhesion of Staphylococcus aureus to human corneocyte envelope proteins. Infect Immun 77, 2408-2416.

Fitzgerald, J. R., Foster, T. J. \& Cox, D. (2006a). The interaction of bacterial pathogens with platelets. Nat Rev Microbiol 4, 445-457.

Fitzgerald, J. R., Loughman, A., Keane, F., Brennan, M., Knobel, M., Higgins, J., Visai, L., Speziale, P., Cox, D. \& Foster, T. J. (2006b). Fibronectin-binding proteins of Staphylococcus aureus mediate activation of human platelets via fibrinogen and fibronectin bridges to integrin GPIIb/IIIa and IgG binding to the Fc $\gamma$ RIIa receptor. Mol Microbiol 59, 212-230.

Ford, I., Douglas, C. W., Heath, J., Rees, C. \& Preston, F. E. (1996). Evidence for the involvement of complement proteins in platelet aggregation by Streptococcus sanguis NCTC 7863. Br J Haematol 94, 729-739.

Grundmeier, M., Hussain, M., Becker, P., Heilmann, C., Peters, G. \& Sinha, B. (2004). Truncation of fibronectin-binding proteins in Staphylococcus aureus strain Newman leads to deficient adherence and host cell invasion due to loss of the cell wall anchor function. Infect Immun 72, 7155-7163.

Hartford, O. M., Wann, E. R., Hook, M. \& Foster, T. J. (2001). Identification of residues in the Staphylococcus aureus fibrinogenbinding MSCRAMM clumping factor A (ClfA) that are important for ligand binding. J Biol Chem 276, 2466-2473.

Kerrigan, S. W., Douglas, I., Wray, A., Heath, J., Byrne, M. F., Fitzgerald, D. \& Cox, D. (2002). A role for glycoprotein Ib in Streptococcus sanguisinduced platelet aggregation. Blood 100, 509-516.

Kerrigan, S. W., Clarke, N., Loughman, A., Meade, G., Foster, T. J. \& Cox, D. (2008). Molecular basis for Staphylococcus aureus-mediated platelet aggregate formation under arterial shear in vitro. Arterioscler Thromb Vasc Biol 28, 335-340.

Kuipers, O. P., Beerthuyzen, M. M., Siezen, R. J. \& De Vos, W. M. (1993). Characterization of the nisin gene cluster nisABTCIPR of Lactococcus lactis. Requirement of expression of the nisA and nisI genes for development of immunity. Eur J Biochem 216, 281-291.

Loughman, A., Fitzgerald, J. R., Brennan, M. P., Higgins, J., Downer, R., Cox, D. \& Foster, T. J. (2005). Roles for fibrinogen, immunoglobulin and complement in platelet activation promoted by Staphylococcus aureus clumping factor A. Mol Microbiol 57, 804-818.

Miajlovic, H., Loughman, A., Brennan, M., Cox, D. \& Foster, T. J. (2007). Both complement- and fibrinogen-dependent mechanisms contribute to platelet aggregation mediated by Staphylococcus aureus clumping factor B. Infect Immun 75, 3335-3343.

Moreillon, P. \& Que, Y. A. (2004). Infective endocarditis. Lancet 363, 139-149.

Mylonakis, E. \& Calderwood, S. B. (2001). Infective endocarditis in adults. N Engl J Med 345, 1318-1330.

O'Brien, L., Kerrigan, S. W., Kaw, G., Hogan, M., Penades, J., Litt, D., Fitzgerald, D. J., Foster, T. J. \& Cox, D. (2002). Multiple mechanisms for the activation of human platelet aggregation by Staphylococcus aureus: roles for the clumping factors ClfA and ClfB, the serineaspartate repeat protein SdrE and protein A. Mol Microbiol 44, 10331044.

O'Connell, D. P., Nanavaty, T., McDevitt, D., Gurusiddappa, S., Hook, M. \& Foster, T. J. (1998). The fibrinogen-binding MSCRAMM (clumping factor) of Staphylococcus aureus has a $\mathrm{Ca}^{2+}$-dependent inhibitory site. J Biol Chem 273, 6821-6829.

Pawar, P., Shin, P. K., Mousa, S. A., Ross, J. M. \& Konstantopoulos, K. (2004). Fluid shear regulates the kinetics and receptor specificity of Staphylococcus aureus binding to activated platelets. J Immunol 173, 1258-1265.

Petersen, H. J., Keane, C., Jenkinson, H. F., Vickerman, M. M., Jesionowski, A., Waterhouse, J. C., Cox, D. \& Kerrigan, S. W. (2009). Human platelets recognize a novel surface protein PadA on Streptococcus gordonii through a unique interaction involving fibrinogen receptor GPIIbIIIa. Infect Immun 78, 413-422.

Skaar, E. P. \& Schneewind, O. (2004). Iron-regulated surface determinants (Isd) of Staphylococcus aureus: stealing iron from heme. Microbes Infect 6, 390-397.

Skaar, E. P., Humayun, M., Bae, T., DeBord, K. L. \& Schneewind, O. (2004). Iron-source preference of Staphylococcus aureus infections. Science 305, 1626-1628.

Visai, L., Yanagisawa, N., Josefsson, E., Tarkowski, A., Pezzali, I., Rooijakkers, S. H., Foster, T. J. \& Speziale, P. (2009). Immune evasion by Staphylococcus aureus conferred by iron-regulated surface determinant protein IsdH. Microbiology 155, 667-679.

Edited by: J. Lindsay 